\title{
DETERMINAÇÃO DE LOCAIS ÓTIMOS PARA IMPLANTAÇÃO DE TORRES DE VIGILÂNCIA PARA DETECÇÃO DE INCÊNDIOS FLORESTAIS POR MEIO DE SISTEMA DE INFORMAÇÕES GEOGRÁFICAS
}

\author{
Nilton Luís Venturi*, Alzir Felippe Buffara Antunes** \\ *Eng. Cartógrafo, M.Sc. - venturi@klabin.com.br \\ **Eng. Cartógrafo, Dr., Depto. de Geomática, UFPR - felipe@ufpr.br \\ Recebido para publicação: 25/09/2006 - Aceito para publicação: 09/02/2007
}

\begin{abstract}
Resumo
Este artigo teve como objetivo descrever as etapas para a determinação de regiões ótimas para a implantação de torres de vigilância para detecção de incêndios florestais utilizando-se um Sistema de Informações Geográficas (SIG). A área de estudo situa-se na região de Telêmaco Borba (PR). A escolha dos locais das torres de vigilância dependeu da identificação de fatores relacionados ao comportamento humano, identificados neste artigo como ameaça, e no conhecimento da vulnerabilidade do ambiente. A identificação desses fatores conduziu à elaboração de um mapa de risco de incêndio, utilizado como referência para a escolha dos locais de implantação das torres. As variáveis relacionadas à distância entre as torres e seu posicionamento em áreas de maior altitude também foram analisadas. A metodologia proposta levou a uma melhoria na cobertura de visibilidade, aumentando-se a área visível pelas torres em 13.375 ha. Nas regiões identificadas com risco de incêndio alto a elevado, o aumento da visibilidade pelas torres foi de 5.935 ha, correspondendo a $44,37 \%$ da área que se tornou visível.

Palavras-chave: Incêndios florestais; SIG; riscos de incêndio; torres de incêndio.
\end{abstract}

\begin{abstract}
Determination of optimum places for implantation of forest fire towers by means of geographic information system. The purpose of this research was to determine the best places for the location of forest fires towers by means of Geographic Information System (GIS). The pilot area is located in the vicinity of the municipality of Telemaco Borba-Parana, Brazil. The choice of the locations for the towers depends on factors related to the human behavior where considered hazardous. The vulnerability of the environment was also taken into account. The identification of fire hazard and vulnerability factors were used as a basic reference to determine where to place the towers. The variables related to the distance between the towers and their positioning in areas of higher altitude also had been considered. The resulting model improved the previous existing system and enabled an increase of cover on 13.375 ha in the visible areas. In the regions identified with high fires risk the increase on the visibility of the towers was 5.935 ha, corresponding to $44.37 \%$ of the area that became detectable through this model.

Keywords: Forestry fires; GIS; fire risk; fire hazard; fire towers.
\end{abstract}

\section{INTRODUÇÃO}

A cobertura florestal de espécies nativas vem sendo reduzida ao longo dos últimos anos no Brasil e no mundo devido às explorações predatórias da madeira e à expansão das fronteiras agrícolas que em muitos casos está intimamente atrelada ao uso do fogo para limpeza da área. A implantação de uma rede de torres de vigilância com vistas à detecção de incêndios florestais demanda estudos das características topográficas da região, cálculo do alcance visual dos operadores das torres e análises de mapas de risco de incêndio com base nos registros de ocorrências anteriores. Em geral, a localização das torres é realizada de forma não automatizada. A utilização de Sistemas de Informações Geográficas (SIG) para detecção de 
incêndios florestais garante maior precisão na identificação do foco inicial do incêndio, proporcionando agilidade nas tomadas de decisão por parte da equipe responsável pelo primeiro combate.

O escopo desta pesquisa foi desenvolver uma metodologia para apoiar a etapa de prevenção a incêndios florestais utilizando-se Sistemas de Informações Geográficas. A estruturação do sistema para a determinação de locais ótimos para implementação das torres de vigilância teve ainda como objetivos:

- identificar as áreas de maior risco de ocorrência de incêndios florestais, analisando-se as ameaças e vulnerabilidade do ambiente;

- avaliar a melhor localização e o número de torres de vigilância de incêndios florestais necessárias para cobrir determinada área;

- analisar a eficiência do modelo de distribuição espacial das torres de vigilância através da análise de visibilidade geral de todas as áreas e análise de visibilidade específica das áreas de maior risco de incêndios.

\section{MATERIAL E MÉTODOS}

\section{Caracterização da área de estudo}

$\mathrm{O}$ estudo foi realizado nas fazendas pertencentes à empresa Klabin no Paraná, englobando os municípios de Telêmaco Borba, Ortigueira, Imbaú, Tibagi, Reserva, Ipiranga e Cândido de Abreu, conforme mostra a figura 1 .

A vegetação natural pertence ao bioma da Floresta Atlântica, caracterizada como Floresta Ombrófila Mista. A distribuição espacial das áreas de conservação favorece um excelente hábitat para a vida animal, devido à formação de corredores de floresta nativa, facilitando o deslocamento de animais silvestres.

O plantio de espécies comerciais iniciou-se na década de 50, com a introdução do gênero pinus estruturados em "talhões", que é uma unidade de manejo onde se aplicam as atividades silviculturais. Atualmente, a área de estudo possui 15.937 talhões, com plantios de eucalipto, pinus, araucária e outras espécies.

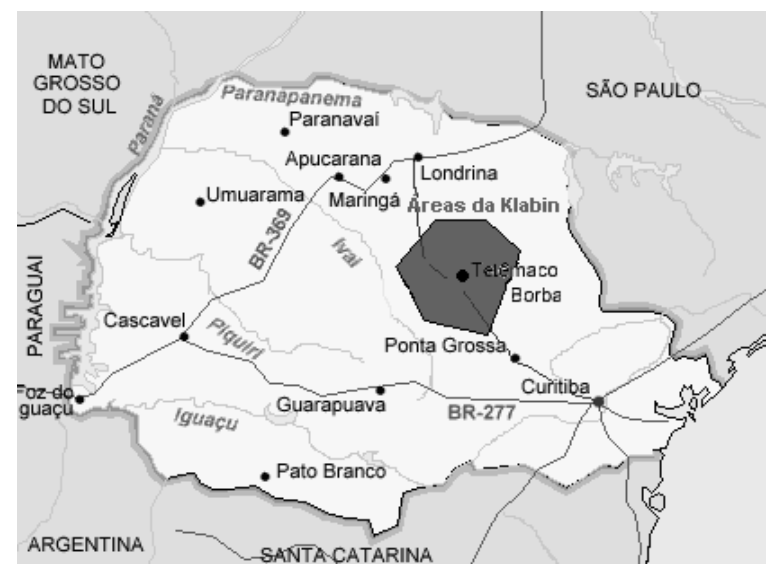

Figura 1. Localização das áreas do estudo em relação ao estado do Paraná.

Figure 1. Study area in Paraná State, Brazil.

\section{Metodologia proposta}

O processo inicial consistiu na determinação de regiões potencialmente perigosas, analisando-se os fatores "ameaça" e "vulnerabilidade" à ocorrência de incêndios, a fim de mapear as áreas de risco, procedimento utilizado como referência para a escolha dos locais para implantação das torres de vigilância.

A ameaça decorre de fatores ligados às causas naturais ou à modificação antrópica do meio. Incêndios decorrentes de causas naturais no Brasil são originados em geral por raios, que por seu caráter aleatório não podem ser identificados a priori. A abordagem utilizada para a determinação do fator 
ameaça baseou-se no mapeamento dos fatores relacionados com o comportamento humano, expressos pelos focos de incêndio identificados pelas torres de vigilância pré-existentes e nas análises do mapa que identificam feições construídas pelo homem que possam causar o início de um processo de combustão.

Com a vulnerabilidade procurou-se identificar fatores relacionados ao meio ambiente que propiciam a propagação de um incêndio. Esses fatores compreendem o clima e suas complexidades em termos de escala de atuação e sazonalidade, o tipo da cobertura vegetal e sua disposição na natureza e as características topográficas da região, como a declividade e orientação das encostas. $\mathrm{O}$ estudo dos componentes atrelados aos aspectos da ameaça e da vulnerabilidade conduz à identificação do risco de incêndio.

A metodologia proposta para determinação do melhor local para implantação de torres de vigilância está estruturada segundo o fluxograma da figura 2. Para a determinação do mapa de risco de incêndio florestal, utilizou-se a álgebra de mapas, mostrado figura 3.

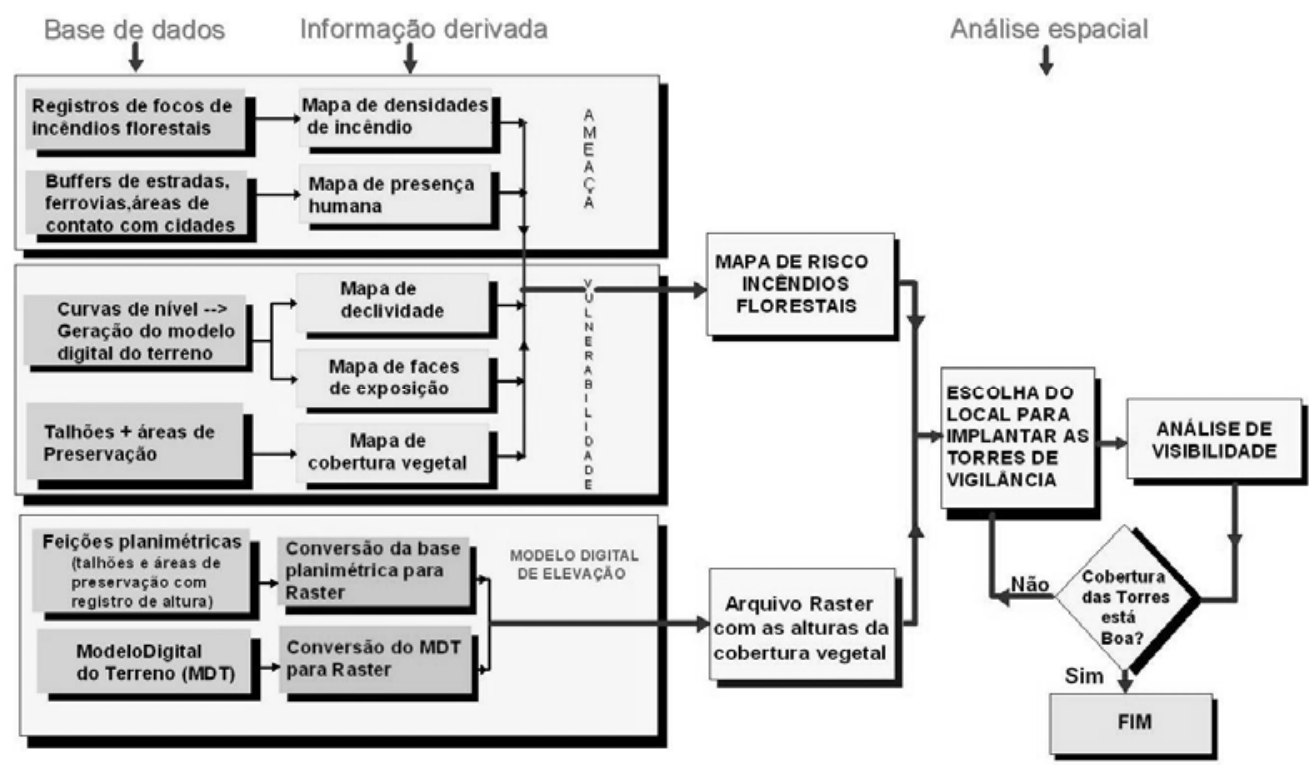

Figura 2. Fluxograma da metodologia adotada para implantação de torres de vigilância.

Figure 2. Flow diagram of the adopted methodology.

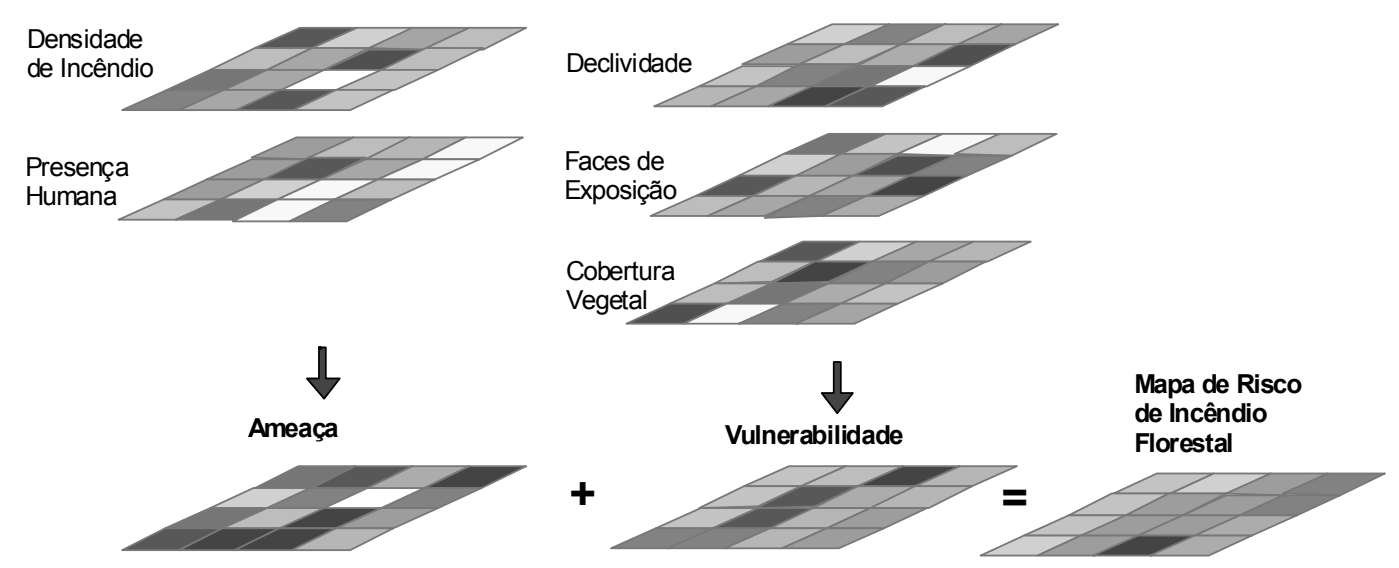

Figura 3. Elaboração do mapa de risco de incêndio através da álgebra de mapas.

Figure 3. Algebra of maps methodology to generate the fire risk map.

FLORESTA, Curitiba, PR, v. 37, n. 2, mai./ago. 2007. 


\section{Análise dos registros dos incêndios florestais}

A primeira análise realizada para a determinação de fatores ligados à ameaça foi o levantamento dos incêndios florestais ocorridos entre os anos de 2001 a 2005. Esses dados foram obtidos através da detecção feita pela rede de torres de vigilância existentes e utilizados como base para análise da distribuição espacial dos incêndios. Iniciou-se a compilação dessas informações através da recuperação das coordenadas registradas pelo software de triangulação denominado "Torres". Desenvolvido em ambiente Arcview 9.0 Avenue, o subsistema inicialmente apresenta uma tela para inserção dos azimutes, dos incêndios visualizados pelas torres. Após o operador da central de rádio preencher os azimutes o aplicativo calcula as coordenadas da interseção e indica o local do incêndio através da janela do ArcView.

A fim de realizar uma futura operação algébrica entre mapas baseados em características distintas, foi aplicada a função densidade ao tema vetorial com os focos triangulados pelas torres. A utilização do cálculo da densidade sobre os focos detectados teve como objetivo a análise da distribuição espacial do fenômeno fogo, procurando-se determinar regiões com graus diferenciados de susceptibilidade.

\section{Análise do comportamento humano}

A segunda análise para a determinação da ameaça existente na área de estudo foi direcionada para o aspecto da influência humana na alteração da paisagem. Consultou-se a tabela de registros de incêndios entre os anos de 1965 a 2005, ocorridos no interior das propriedades da Klabin ou em áreas de terceiros onde a empresa ajudou a apagar o fogo.

A verificação das informações sobre os motivos dos incêndios ocorridos durante os últimos 40 anos foi determinante para a criação de coeficientes de risco segundo as feições construídas pelo homem ou sob influência direta. Para a identificação das áreas de influência do comportamento humano foram criados buffers (operadores de área), com distâncias variando de acordo com o tipo de feição. A tabela 1 mostra a relação entre cada feição, tamanho e peso atribuído. A análise dessa classificação resultou na criação do mapa de influência do comportamento humano.

Tabela 1. Feições com influência humana.

Table 1. Human features influence.

\begin{tabular}{lcc}
\hline Feição & Tamanho do Buffer & Risco \\
\hline Estradas públicas & $100 \mathrm{~m}$ & 5 \\
Áreas de divisa com vilas, cidades & $100 \mathrm{~m}$ & 5 \\
Áreas de divisa com reflorestamento de terceiros ou agricultura & $100 \mathrm{~m}$ & 5 \\
Estradas particulares & $30 \mathrm{~m}$ & 4 \\
Ferrovias & $30 \mathrm{~m}$ & 3 \\
Rede de energia elétrica & $230 \mathrm{~m}$ & 2 \\
\hline
\end{tabular}

\section{Composição do mapa de ameaça}

O mapa final correspondente ao fator ameaça foi gerado utilizando-se a operação algébrica entre os mapas da densidade de focos de incêndio e da influência da presença humana. Adicionou-se o mapa de densidade, com suas cinco classes, ao mapa de presença humana, estruturado com peso unitário para áreas sob influência humana e nulo para áreas sem influência.

\section{Obtenção do mapa de declividades}

A determinação do risco de incêndio compreende, além do aspecto ameaça expresso nesta pesquisa pelos mapas de densidade e de presença humana, o aspecto da vulnerabilidade do ambiente. A vulnerabilidade foi primeiramente analisada através da determinação da declividade, pois essa variável topográfica condiciona o aumento da velocidade de propagação das chamas e o direcionamento do avanço do fogo. Utilizou-se a classificação adaptada de Soares (1985), que relaciona a declividade com o risco de incêndio florestal, ordenado de forma crescente, de nulo a extremo, conforme ilustra a tabela 2.

\section{Determinação do mapa de faces de exposição}

A segunda análise da vulnerabilidade do ambiente direcionou-se na determinação da face de exposição relacionada à parte do relevo onde a incidência luminosa é maior, acarretando aquecimento diferenciado do material combustível e conseqüente maior rapidez de ignição. O mapa foi obtido através 
do modelo digital de elevação. Para a determinação do risco de cada face de exposição, foi elaborada uma tabela segundo classificação utilizada por Ferraz et al. (1998), que adaptou valores utilizados no hemisfério Norte para o hemisfério Sul, ilustrados na tabela 3.

Tabela 2. Relação entre classes de declividade e risco de incêndio.

Table 2. Relation between slope and fire risk.

\begin{tabular}{lcc}
\hline Declividade em \% & Risco & Peso \\
\hline 0 a 15 & Baixo & 1 \\
$16-25$ & Médio & 2 \\
$26-35$ & Alto & 3 \\
$36-45$ & Muito alto & 4 \\
$>46$ & Extremo & 5 \\
\hline
\end{tabular}

Tabela 3. Relação entre a exposição do terreno e o risco de incêndio.

Table 3. Relation between terrain exposure and fire risk.

\begin{tabular}{lcc}
\hline Face de exposição & Risco & Peso \\
\hline Plano, sul & Nulo & 0 \\
Sudeste, sudoeste & Baixo & 1 \\
Leste & Médio & 2 \\
Nordeste & Alto & 3 \\
Noroeste, oeste & Muito alto & 4 \\
Norte & Extremo & 5 \\
\hline
\end{tabular}

\section{Determinação do mapa de cobertura vegetal}

A terceira análise sob o aspecto da vulnerabilidade do ambiente foi a elaboração do mapa de cobertura vegetal, associando-se os respectivos riscos de incêndio. Elaborou-se um mapa com a ocupação do solo de acordo com as classes de vegetação nas propriedades estudadas, atribuindo-se pesos proporcionais em relação à sua periculosidade de incêndio. Para a determinação do tipo de cobertura vegetal no interior das propriedades, utilizaram-se os registros do banco de dados denominado cadastro florestal, relacionando o talhão à espécie plantada. O peso das classes de vegetação no interior das propriedades foi estabelecido através de consulta bibliográfica, adaptando-se a classificação estabelecida por Oliveira et al. (2002) para coberturas vegetais no estado do Paraná (Tabela 4). O mapa da figura 8 ilustra o risco de incêndio em função da cobertura vegetal, conforme os pesos relacionados na tabela 4.

Tabela 4. Relação entre o tipo de vegetação e risco de incêndio.

Table 4. Relation between vegetation and fire risk.

\begin{tabular}{lcc}
\hline Tipo de vegetação & Risco & Peso \\
\hline Áreas sem cobertura vegetal (estradas, solo exposto...) & Nulo & 0 \\
Áreas em descanso (disponíveis para futuro plantio) & Baixo & 1 \\
Florestas & Médio & 2 \\
Plantios de folhosas & Alto & 3 \\
Plantios de araucária & Muito Alto & 4 \\
Plantios de coníferas & Extremo & 5 \\
\hline
\end{tabular}

\section{Composição do mapa de vulnerabilidade}

O mapa de vulnerabilidade expressa a soma dos fatores relacionados às características topográficas e da cobertura vegetal. O mapa de vulnerabilidade foi gerado através da soma dos mapas de declividades, faces de exposição e cobertura vegetal, permitindo uma análise espacial das regiões de maior risco correlacionada com as características físicas do meio (Figura 3).

\section{Composição do mapa de risco de incêndios florestais por meio de álgebra de mapas}

O mapa de risco de incêndios florestais abordou os aspectos ameaça e vulnerabilidade. A ameaça está representada por meio dos mapas de densidade de incêndios e mapa de presença humana, e a vulnerabilidade, expressa pelos mapas de declividade, faces de exposição e cobertura vegetal. A 
composição do mapa final de risco integrou os mapas de ameaça e vulnerabilidade, segundo o modelo adaptado de Castañeda (1997), sendo: Mapa Risco $=0,5 *$ ameaça $+0,5 *$ vulnerabilidade.

\section{Criação de modelo digital de elevação com a altura da vegetação}

Objetivando determinar as áreas visíveis em um sistema de torres de vigilância a incêndios florestais, adotou-se um modelo que permitisse a representação da superfície da terra considerando-se as alturas da vegetação, constituída em sua grande maioria por florestas e por plantios de espécies florestais comerciais. O elevado grau de conservação permitiu o estabelecimento de uma altura padrão para a floresta em 18 metros. Parcelas de inventário florestal em áreas de florestas nativas contribuíram para a definição dessa altura padrão.

\section{Escolha do melhor local para implantação das torres de vigilância}

A rápida detecção de um incêndio florestal é fundamental para o sucesso das etapas de controle e extinção. Para a escolha dos locais de implantação das torres de vigilância, as variáveis estabelecidas foram:

- distância de visibilidade das torres;

- relevo;

- proximidade com as regiões classificadas com risco alto ou extremo.

$\mathrm{Na}$ análise de visibilidade, adotou-se como alcance visual a distância de $15 \mathrm{~km}$, considerando-se que nessa região exista a cobertura de pelo menos duas torres que observem o mesmo alvo. A utilização dessa distância foi embasada em estudos realizados por Soares (1984) nessa mesma região do Paraná, considerando-se os efeitos do clima e topografia. A resolução espacial dos arquivos matriciais ou raster foi definida em 30 metros, porque valores com resolução espacial menores acarretam um esforço computacional elevado sem melhorias significativas na análise espacial. A elaboração do mapa das regiões com alto risco de ocorrência de incêndios, considerando-se as variáveis ameaça e vulnerabilidade do ambiente, demonstrou a necessidade de vigilância ostensiva pelas torres em sete locais especificos, seja pela presença de fatores ambientais ou pela influência humana.

A implantação das torres de vigilância decorreu da análise concomitante das áreas críticas apontadas pelo mapeamento de risco, da escolha de locais com maiores altitudes e da distância entre as torres.

\section{Avaliação da visibilidade das torres em conjunto com o mapa de risco de incêndios}

Uma vez definidas as áreas com maior risco de incêndio, a análise seguinte foi dirigida à escolha dos locais para implantar as torres. Observando-se as altitudes expressas pelo modelo digital do terreno, definiram-se pontos na base cartográfica correspondentes aos possíveis espaços de implantação das torres. A distância ótima entre as torres foi considerada em $15 \mathrm{~km}$. Muitas vezes, essa distância não pode ser alcançada devido às características topográficas, como, por exemplo, a existência de áreas montanhosas a mais de $15 \mathrm{~km}$. Nesses casos, o aumento da distância entre as torres foi compensado pela elevação na altitude da torre.

A análise sobre a eficiência da distribuição espacial das torres utilizou o modelo de visibilidade que contém a altura da cobertura vegetal. Após a escolha preliminar das posições ocupadas pelas torres, procedeu-se o cálculo de quais áreas eram diretamente visíveis pelo observador. $\mathrm{O}$ resultado desse estudo foi expresso por meio de mapas de visibilidade, atribuindo-se valores às células (pixels) correspondentes às regiões visíveis do mapa, de acordo com o número de torres que pudessem detectar o incêndio. Os valores dos pixels variaram de zero, quando nenhuma torre observava o local, até $n$, correspondendo ao número de torres que avistaram aquele local.

Sobre o mapa de visibilidade, realizaram-se duas análises, uma geográfica e outra estatística. $\mathrm{Na}$ primeira análise, compararam-se os mapas de visibilidade com o mapa de risco de incêndio, com o objetivo de detectar zonas com recobrimento superabundante, suficiente ou insuficiente, sob os aspectos geográficos de detecção e sob os aspectos de perigo de incêndio. Na segunda análise, as áreas nãovisíveis e visíveis foram quantificadas para avaliar a eficiência do sistema de torres.

Após a verificação dos resultados das análises geográficas e estatísticas, alteraram-se as posições das torres, visando-se aperfeiçoar o sistema de detecção sob essas duas análises. Esse modelo de interação, com a troca dos locais de implantação das torres, continuou até a constatação do 
posicionamento ótimo, alcançado por meio da verificação da cobertura efetiva em áreas classificadas como críticas no mapeamento de risco conjuntamente com a quantificação da área visível do modelo. Foram comparados os resultados obtidos pela metodologia proposta com o sistema de torres de vigilância atualmente existente na empresa. A partir desses estudos, elaboraram-se relatórios com sugestões para melhorias no sistema de vigilância a incêndios florestais baseados em torres de observação.

\section{RESULTADOS E DISCUSSÃO}

Analisando-se os registros dos incêndios florestais, criou-se o mapa de densidade de ocorrências de focos de incêndio (Figura 4), permitindo uma avaliação inicial da ameaça sofrida pelo ambiente, caracterizada através de uma descrição espacial contínua oferecida pelo modelo adotado. O mapa do comportamento humano (Figura 5) ilustra os locais onde a influência do homem oferece ameaça ao início de um incêndio florestal.

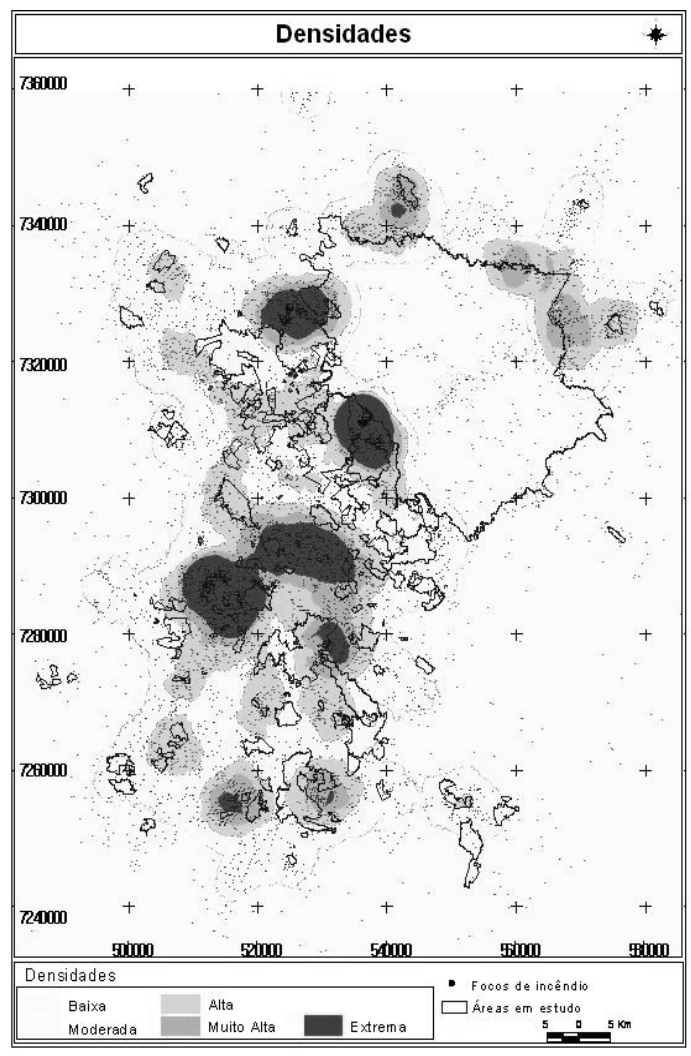

Figura 4. Mapa de densidade dos incêndios. Figure 4. Fire occurrence density map.

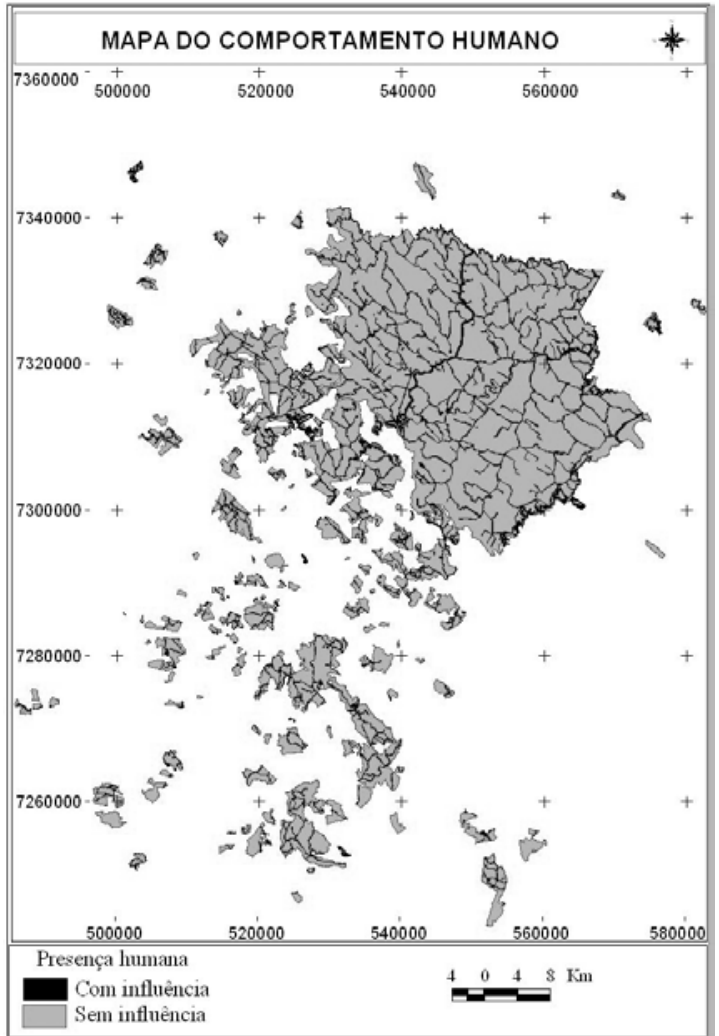

Figura 5. Mapa da influência da presença humana.

Figure 5. Human influence map.

As análises preliminares sob o aspecto da ameaça obtidas a partir desse mapa permitiram a identificação de 4 regiões com risco variando de muito alto a extremo sob o ponto de vista da ameaça, correspondendo a 4.315,22 ha.

As áreas com risco médio a alto totalizaram 106.150,55 ha. Na fazenda Monte Alegre, três locais foram incluídos nessas classes. A primeira região, localizada no nordeste da fazenda, sofre influência de uma rodovia estadual com alto tráfego. Na parte norte localiza-se um grande maciço de reflorestamento limítrofe à propriedade, com presença também da rodovia estadual PR 160. A terceira região está localizada junto à ferrovia, na parte central da fazenda. 
Outras áreas classificadas com risco médio a alto localizam-se em fazendas que possuem vizinhos que utilizam agricultura e pasto, com uso do fogo para a limpeza do terreno. As áreas classificadas com risco baixo a moderado totalizaram 91.627,67 ha e correspondem às regiões com pouca influência da ação do homem. O mapa representando os fatores ligados à ameaça, resultado da soma entre o mapa de densidade e o mapa da presença humana, está ilustrado na figura 6.

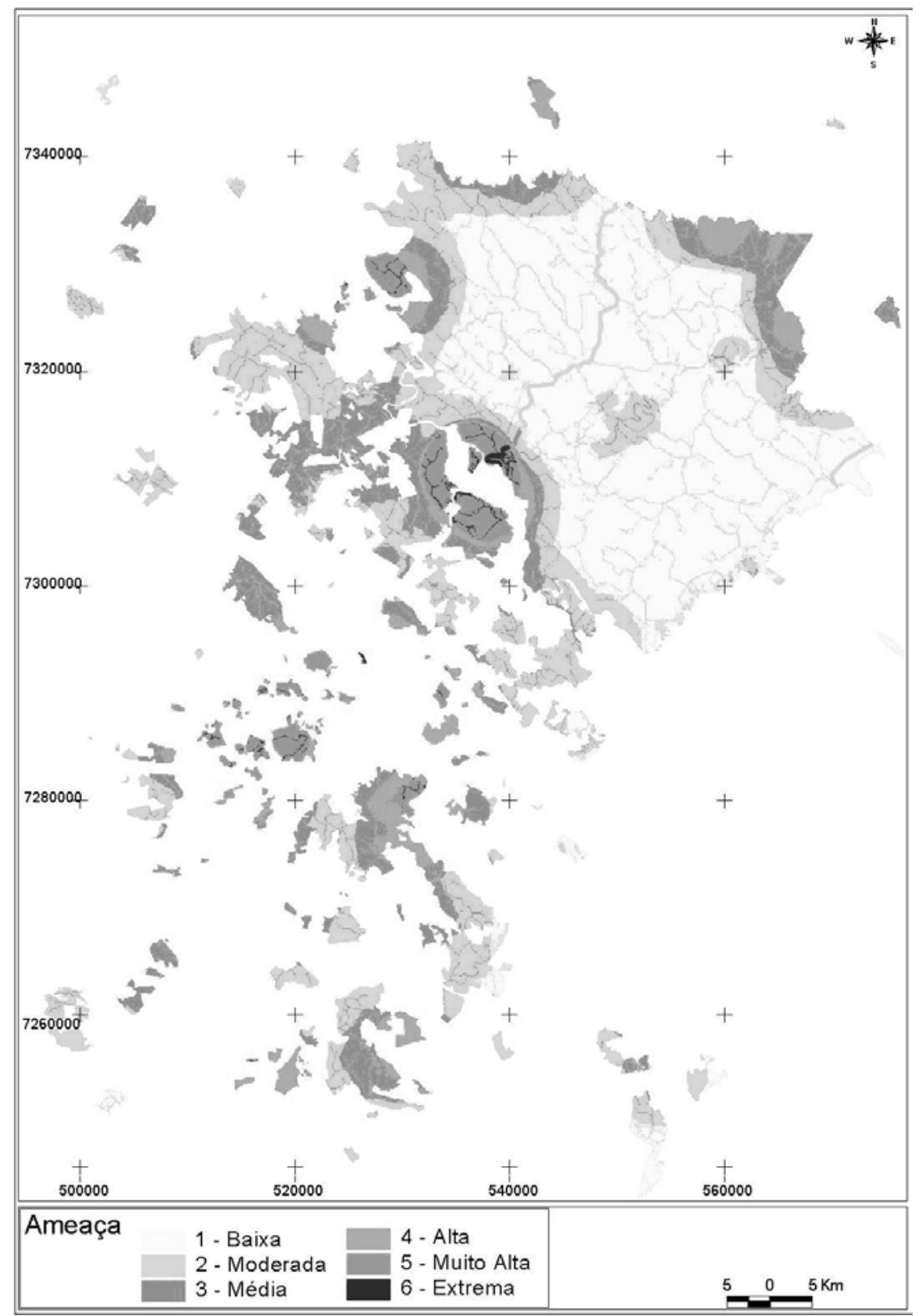

Figura 6. Mapa da ameaça.

Figure 6. Fire hazard map.

Elaborou-se o mapa de declividades (Figura 7) associado ao risco de incêndio, o mapa de faces de exposição e o mapa de risco de incêndio em função da cobertura vegetal (Figura 8). 
Através da soma dos mapas de declividade, faces de exposição e cobertura vegetal, obteve-se o mapa de risco de incêndio florestal em função da vulnerabilidade do ambiente (Figura 9).

De acordo como o modelo, pôde-se detectar que as áreas classificadas com baixa vulnerabilidade somaram 18.046,86 ha. A vulnerabilidade classificada como alta a extrema somaram 116.819 ha , ou $57,80 \%$ da área total, evidenciando uma região onde a associação de materiais combustíveis com a declividade e faces de exposição tornam o ambiente propício para a propagação de incêndios de grandes proporções. O mapa de vulnerabilidade mostra uma distribuição espacial das áreas classificadas como risco muito alto de forma homogênea, estando presente em praticamente todas as fazendas pertencentes à Klabin. Essa característica está associada, em parte, ao arranjo dos plantios, onde a presença de talhões de coníferas e folhosas, que estão distribuídos lado a lado com corredores de florestas, ocupa grandes extensões geográficas. As áreas de preservação correspondem a mais de 85.000 ha, possuindo menor quantidade de material combustível associado a um microclima mais ameno, evitando a formação de grandes blocos contínuos classificados com vulnerabilidade alta a extrema.

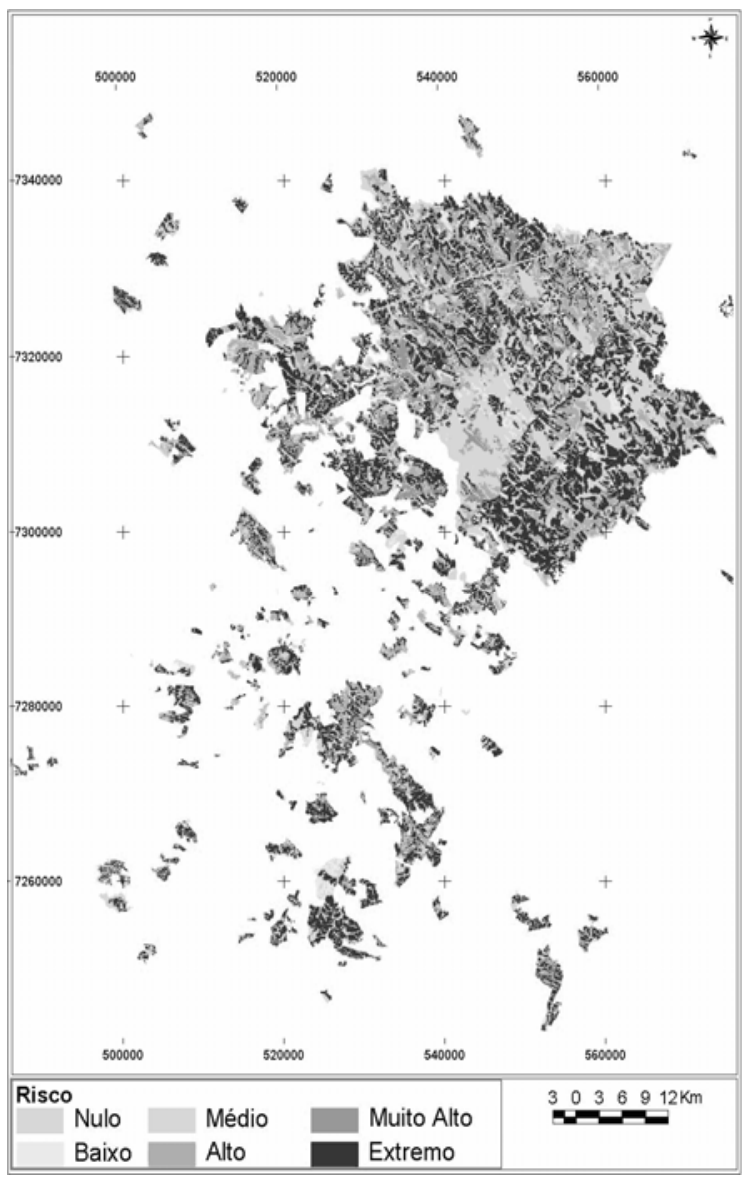

Figura 7. Mapa de declividade.

Figure 7. Slope map.

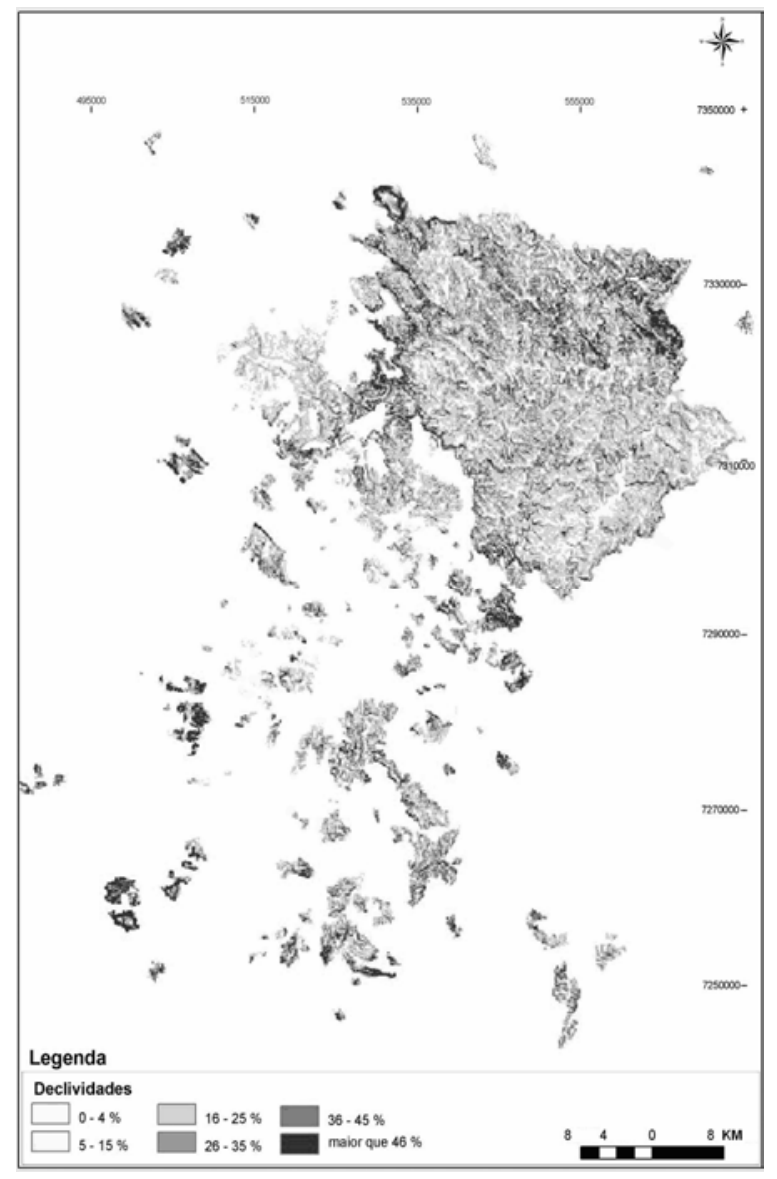

Figura 8. Mapa de risco de incêndio em função da cobertura vegetal.

Figure 8. Fire risk map related to vegetation coverage.

Uma vez determinados os fatores relacionados à ameaça e à vulnerabilidade do ambiente, gerou-se o mapa final de risco de incêndio florestal (Figura 10), proporcionando uma análise geográfica detalhada das regiões mais susceptíveis à ocorrência do fogo. 
Constatou-se que áreas consideradas de baixo risco somaram apenas 1,21\%. Mais da metade da região de estudo possui risco de incêndio classificado como alto, correspondendo a 105.719,08 ha.

Áreas classificadas com risco muito alto somaram 19,91\%, índice relativamente alto, que em conjunto com as áreas classificadas com risco extremo $(0,76 \%)$ mereceram atenção especial nas análises futuras deste estudo, em que o mapa de risco, de acordo com a figura 11, norteou a escolha de locais para a implantação das torres de vigilância.

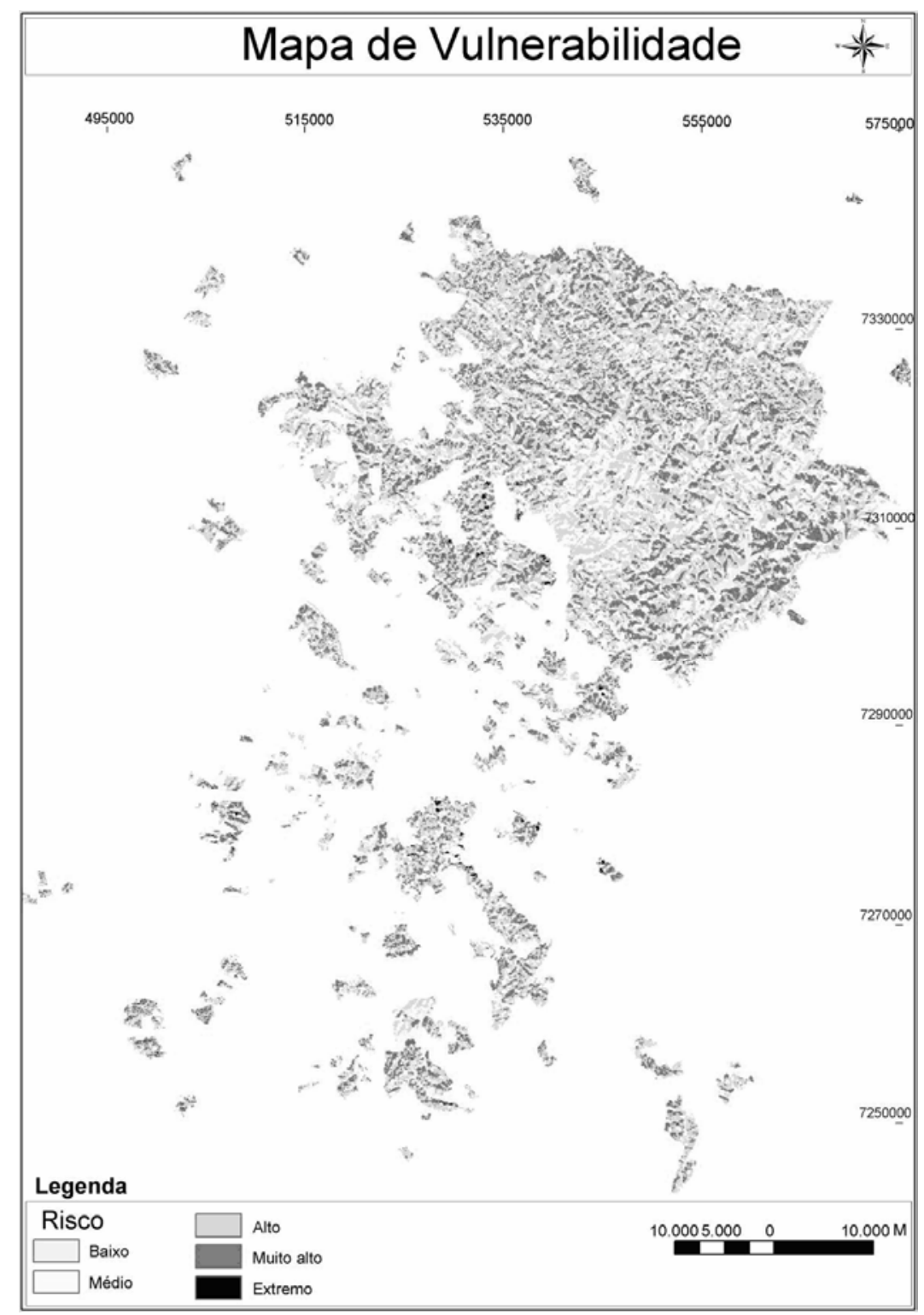

Figura 9. Mapa de vulnerabilidade.

Figure 9. Vulnerability map.

Em um sistema de detecção de incêndios florestais através de torres de incêndio, a visibilidade de 100 \% da região só é possível em pequenas propriedades. Em grandes áreas, a vigilância efetiva de toda a região demanda uma quantidade muito elevada de torres, tornando o sistema inviável economicamente. 
Verificou-se que, para as propriedades em estudo, seriam necessárias 23 torres para garantir um sistema de vigilância baseado nos critérios estabelecidos. Do sistema atual, com 18 torres, 14 permaneceram em seu local por apresentarem condições topográficas favoráveis, comprovadas pelos cálculos de visibilidade, e 4 torres já existentes foram removidas para outras regiões, permitindo aumentar o índice de visibilidade, principalmente nas áreas identificadas pelo mapa de risco de incêndio florestal.

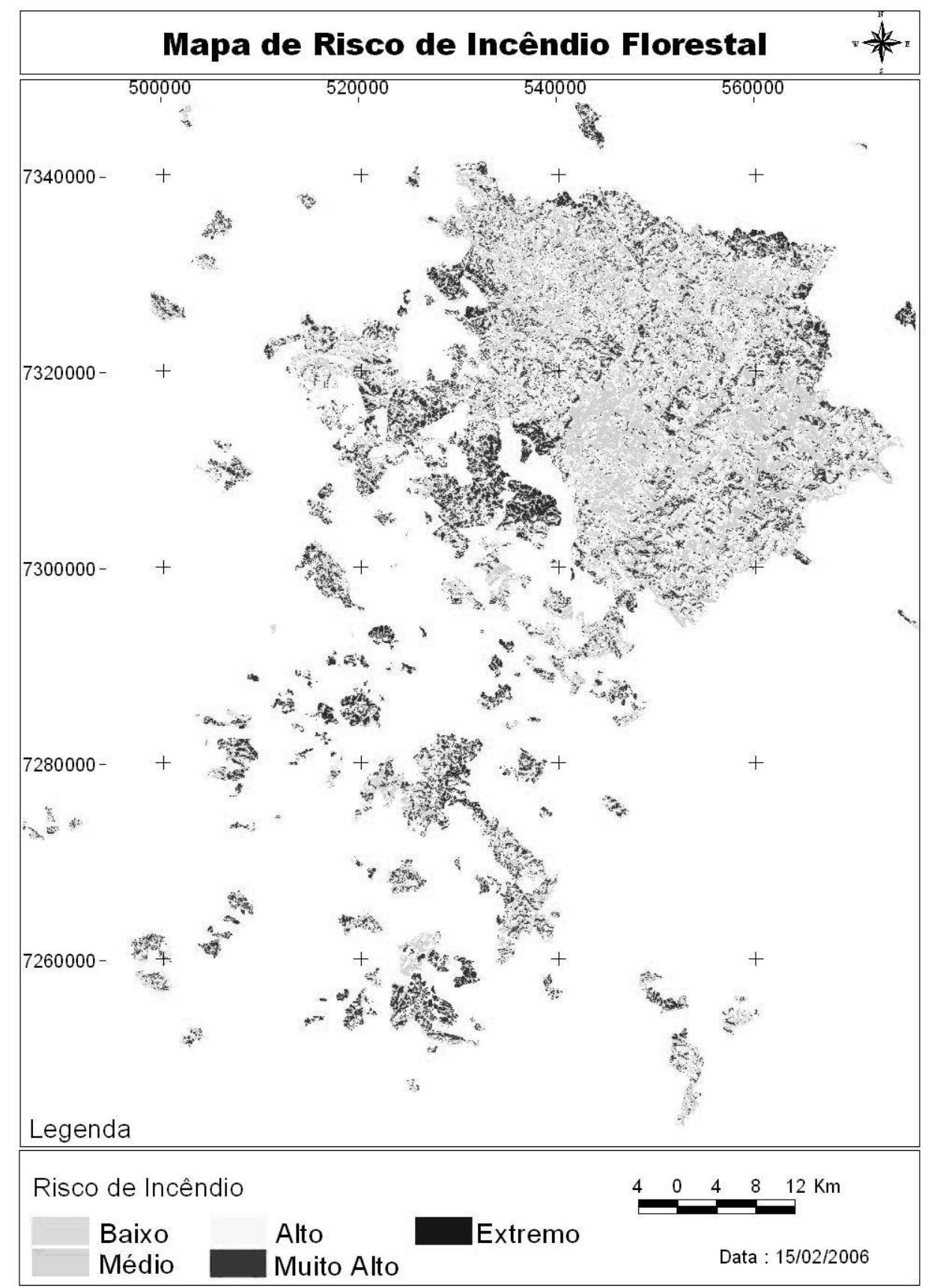

Figura 10. Mapa de risco de incêndio florestal.

Figure 10. Fire risk map. 
Objetivando o recobrimento eficaz da região, incluíram-se mais cinco torres ao sistema nas áreas identificadas com pouca cobertura e com grau elevado de risco de incêndio.

A figura 12 ilustra áreas visíveis e áreas invisíveis de parte da área de estudo. A figura 13 ilustra a configuração atual das torres de vigilância (círculos) e a configuração proposta (triângulos) segundo as análises para a determinação de locais ótimos das torres. Quatorze torres não tiveram sua posição alterada (círculo sobreposto aos triângulos).

Nas análises das sete regiões de maior risco, observou-se um aumento da área visível após a readequação do sistema de vigilância por torres. A tabela 5 quantifica as áreas visíveis de acordo com a localização atual das 18 torres existentes, comparando com a situação proposta, utilizando as 23 torres.

Tabela 5. Comparação entre as áreas visíveis atuais e propostas nas sete áreas de maior risco de incêndio.

Table 5. Comparison between the visible implemented and proposed areas in the seven regions with greater risk.

\begin{tabular}{lcccc}
\hline Região & $\begin{array}{c}\text { Área visível atual } \\
\text { (ha) }\end{array}$ & $\begin{array}{c}\text { Área visível proposta } \\
\text { (ha) }\end{array}$ & $\begin{array}{c}\text { Acréscimo } \\
\text { (ha) }\end{array}$ & (\%) \\
\hline 1 & $2.255,40$ & $4.377,18$ & $2.121,78$ & $48,47 \%$ \\
2 & $6.545,12$ & $7.966,66$ & $1.421,54$ & $17,84 \%$ \\
3 & $2.275,04$ & $3.444,15$ & $1.169,11$ & $33,94 \%$ \\
4 & $6.153,53$ & $6.386,06$ & 232,53 & $3,64 \%$ \\
5 & $3.549,95$ & $3.750,88$ & 200,93 & $5,36 \%$ \\
6 & $8.939,91$ & $10.113,52$ & $1.173,61$ & $11,60 \%$ \\
7 & $12.844,90$ & $13.917,17$ & $1.072,27$ & $7,70 \%$ \\
\hline Total & $42.563,85$ & $49.955,62$ & $7.391,77$ & $14,80 \%$ \\
\hline
\end{tabular}

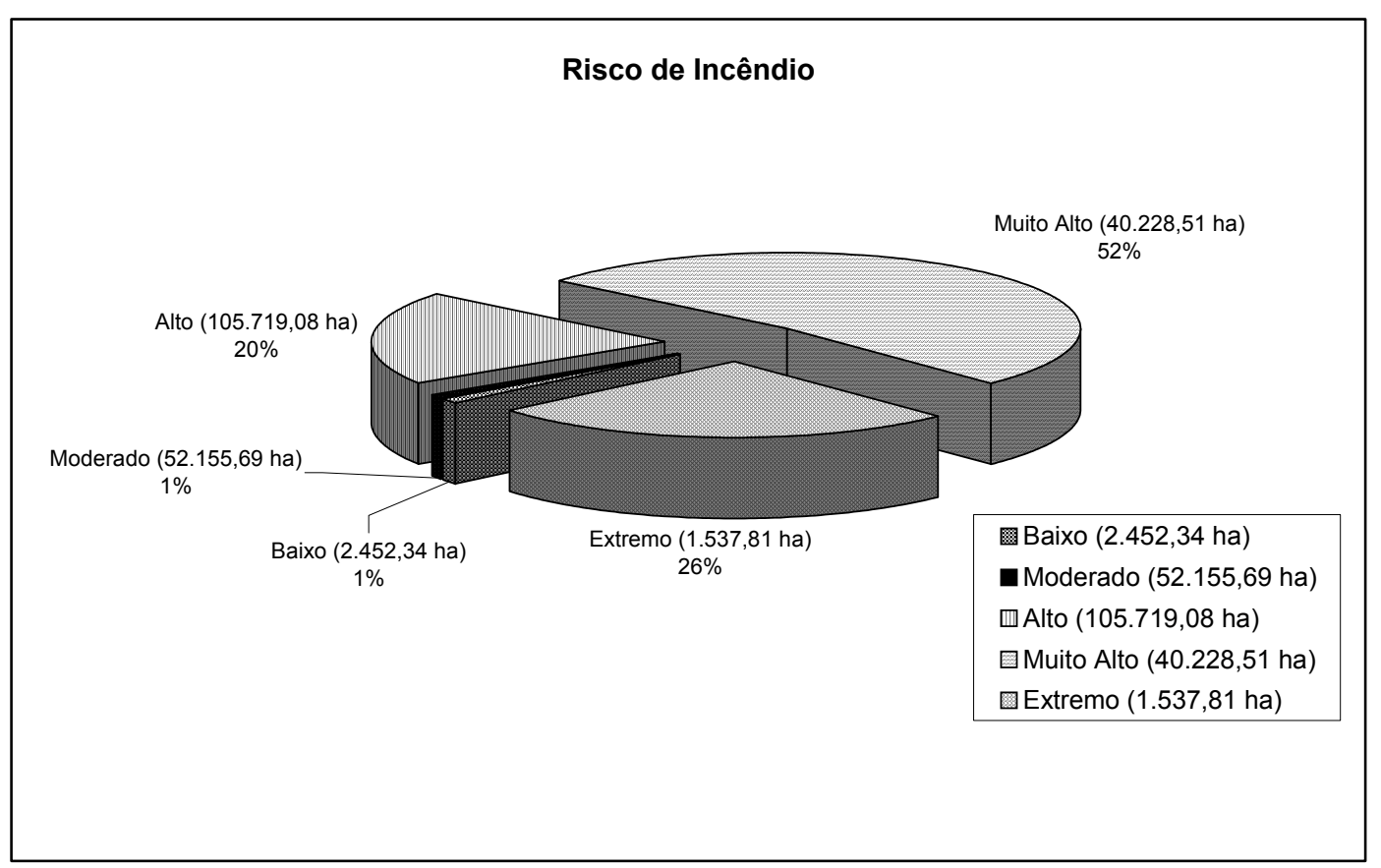

Figura 11. Gráfico do risco de incêndio resultante dos fatores "ameaça" e "vulnerabilidade".

Figure 11. Fire risk levels based on hazard and vulnerability.

Observou-se uma melhora em relação à eficiência de visibilidade total nas sete regiões selecionadas com risco alto a extremo em 14,80 \%. Na figura 14, encontra-se o mapa de visibilidade final, obtido com o uso das 23 torres propostas por este estudo. 


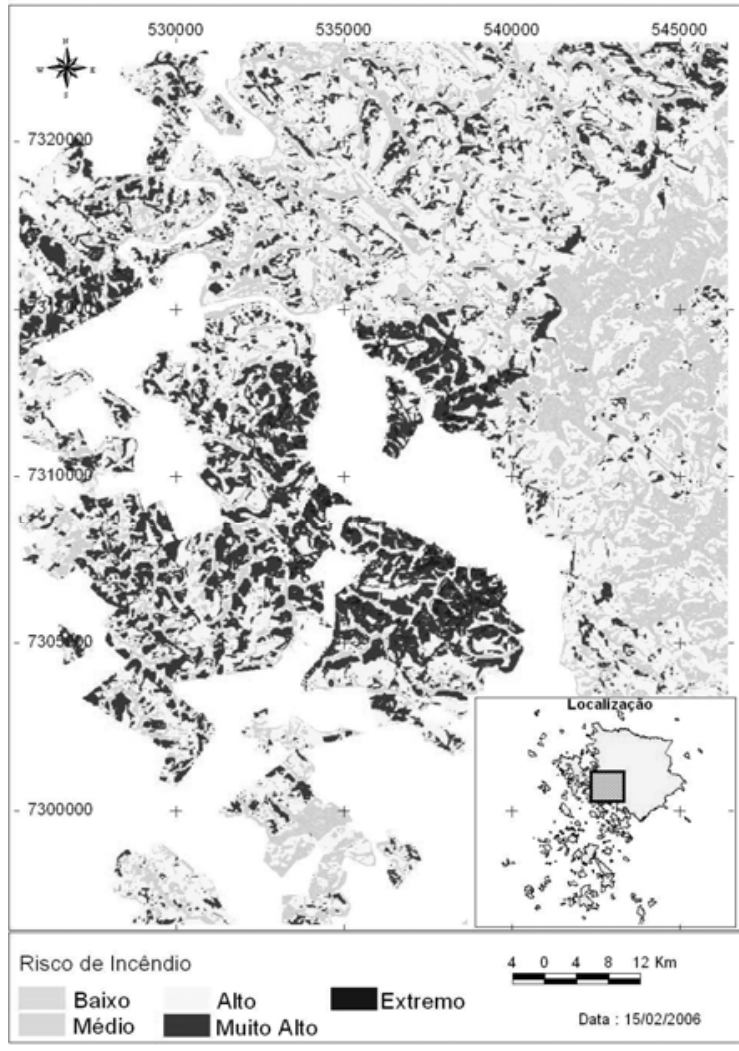

Figura 12. Mapa de visibilidade.

Figure 12. Visibility map.

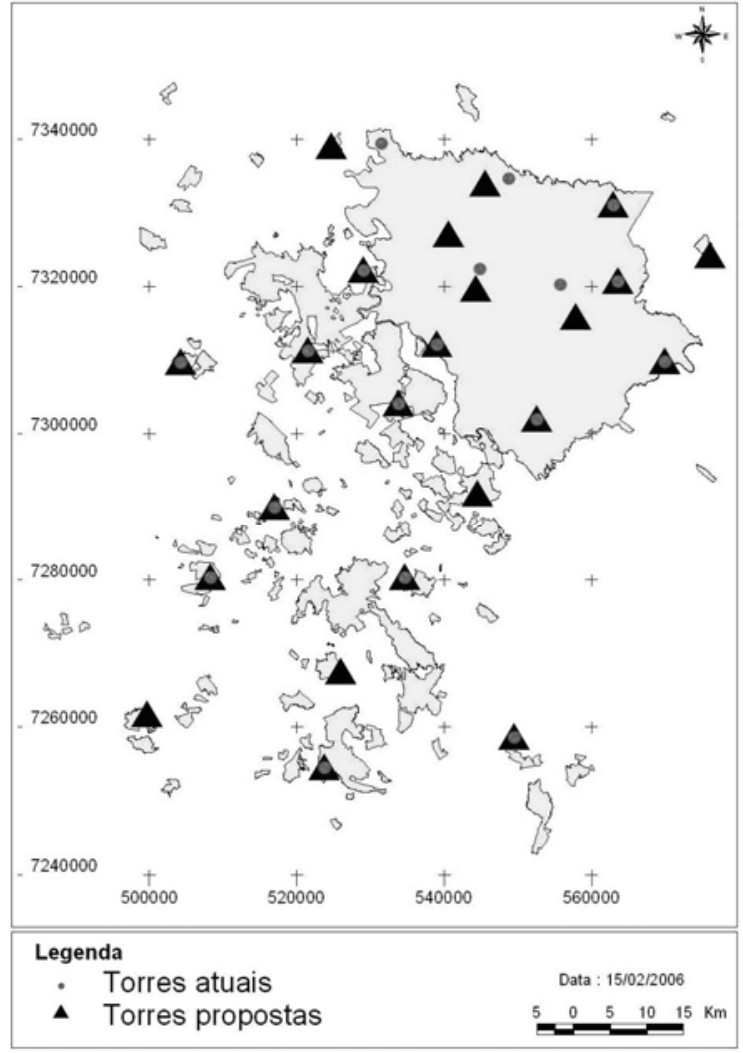

Figura 13. Localização das torres atuais e propostas.

Figure 13. Implemented towers and proposed towers.

\section{CONCLUSÕES E RECOMENDAÇÕES}

O estudo conduzido para a determinação a priori das áreas de maior risco a incêndios florestais mostrou ser bastante eficaz para auxiliar a quantificação do número de torres necessárias para vigiar uma determinada região e para aperfeiçoar a determinação geográfica dos locais para a implantação das torres de vigilância.

Evidenciou-se que, para a escolha do local ótimo na implantação de torres de vigilância, é necessário o conhecimento dos fatores "ameaça" e "vulnerabilidade" expressos através do mapa de riscos de incêndios florestais. A utilização desse mapa como ferramenta de análise das áreas críticas permitiu quantificar e posicionar geograficamente as torres de vigilância de forma eficaz.

Para a determinação do risco de incêndio segundo os critérios de vulnerabilidade e ameaça, conclui-se que o conhecimento dos focos de incêndio ocorridos na região foi de grande importância para a correta integração dos mapas. A elaboração de um banco de dados que contemple o histórico de perturbação da região por incêndios é imprescindível para o aumento da qualidade da informação requerida.

O sistema de detecção de focos de incêndios existente na empresa foi bastante útil na recuperação das informações georreferenciadas, bem como os dados que relacionam o incêndio à data $\mathrm{e}$ hora.

A inclusão das alturas das vegetações no modelo digital do terreno visando o cálculo das áreas cobertas pelas torres, proporcionou a determinação mais realística da visibilidade. Evidenciou-se um acréscimo da área total visível em 13.375,98 ha, correspondendo a 6,62 \%. 


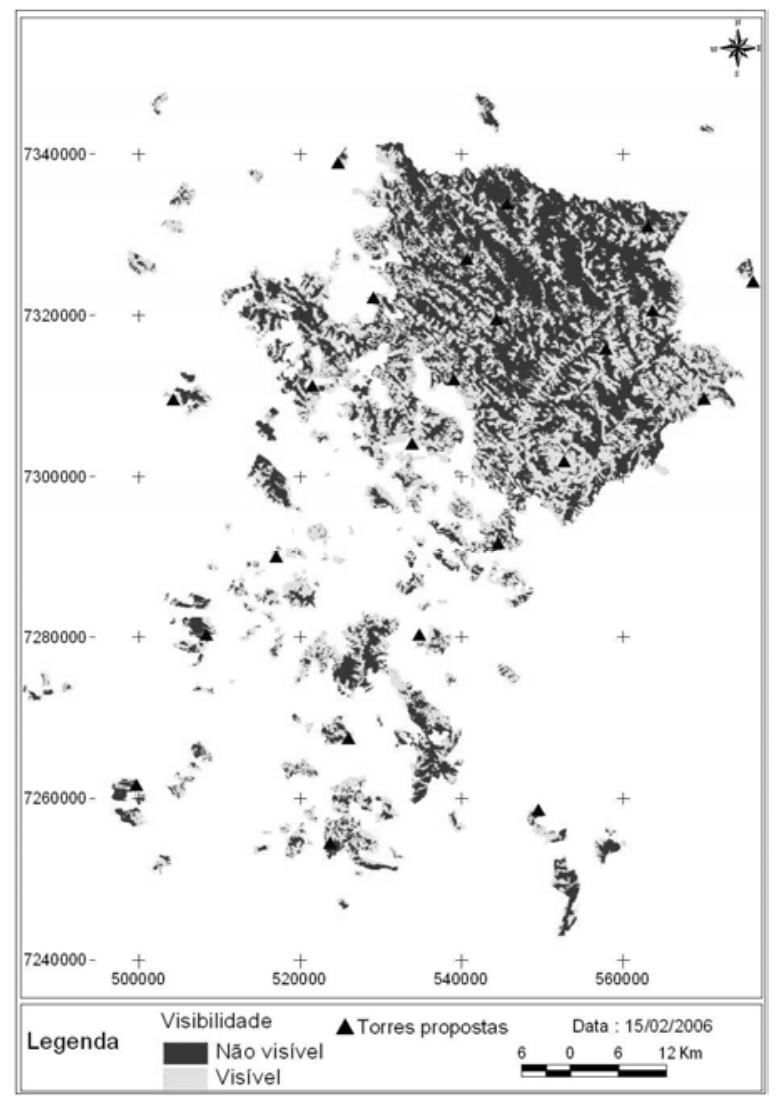

Figura 14. Mapa de visibilidade final após a modificação das torres de vigilância. Figure 14. Final visibility map after the modification of surveillance towers.

Comparando-se o sistema atual de torres de vigilância com o modelo proposto, a quantidade de área classificada com risco alto a extremo que se tornou "visível" aumentou em 5.935 ha, correspondendo a 44,37 \% das áreas que passaram a ser atendidas pelo sistema de vigilância por torres, comprovando a hipótese básica formulada nesta pesquisa.

\section{REFERÊNCIAS}

BATISTA, A. C. Determinação de umidade do material combustível sob povoamentos de Pinus taeda . 61 f. Dissertação (Mestrado em Engenharia Florestal) - Setor de Ciências Agrárias, Universidade Federal do Paraná, Curitiba, 1984.

BAtista, A. C. Avaliação da Queima Controlada em Povoamentos de Pinus taeda L. no Norte do Paraná. 108 f. Tese (Doutorado em Engenharia Florestal) - Setor de Ciências Agrárias, Universidade Federal do Paraná, Curitiba, 1995.

CASTAÑEDA, A. Zonificacion para el manejo de incêndios en plantaciones forestales en Colômbia. Boletin de Proteccion Forestal, Colômbia, n. 2. p. 38-46, 1997.

FERRAZ, S. F. B.; VETTORAZZI, C. A. Mapeamento de risco de incêndios florestais por meio de sistema de informações geográficas (SIG). Scientia Forestalis, Piracicaba, v. 53, p. 39-48, 1998.

FREIRE, S.; CARRÃO, H.; CAETANO, M. R. Produção de cartografia de risco de incêndio florestal com recurso a imagens de satélite e dados auxiliares. Disponível em: $<$ http://www.igeo.pt/Igeo/portugues/Novidades_eventos/eventos/esig2002/p035.pdf $>$. Acesso em: $15 / 02 / 2005$ 
GAYLOR, H. P. Wildfires : prevenction and control . Bowie .USA: Ed. Prentice-Hall, 1974.

KLAVER, J. M.; KLAVER, R. W.; BURGAN, R. E. Using GIS to Assess Forest Fire Hazard in the Mediterranean Region of the United States. Disponível em: $<$ http:/gis.esri.com/library/userconf/proc97/proc97/to300/pap286/p286.htm>. Acesso em: 14/03/2005.

LIU, P. S.; CHOU, Y. H. A grid automation of wildfire growth simulation. Disponível em: $<$ http://gis.esri.com/library/userconf/proc97/proc97/abstract/a158.htm > . Acesso em: 20/04/2005.

LELOUP, M. Elements of Forest fire control. Roma: FAO, 1952. (Forestry Publications, n. 5)

NOGUEIRA, G. S.; RIBEIRO, G. A.; RIBEIRO, C. A. A. S.; SILVA, E. P. Escolha de locais para instalação de torres de detecção de incêndio com auxílio do SIG. Revista Árvore,Viçosa, MG, v. 26, n. 3, 2002.

OLIVEIRA, D. S. Zoneamento de risco de incêndios em povoamentos florestais no norte de Santa Catarina. Dissertação (Mestrado em Ciências Florestais) - Setor de Ciências Agrárias, Universidade Federal do Paraná, Curitiba, 2002.

SOARES, R. V. Incêndios florestais: controle e uso do fogo. Curitiba: Ed.FUPEF, 1985.

SOARES, R. V. Prevenção e controle de incêndios florestais. Curitiba: Ed.FUPEF, 1984.

VENTURI, N. L. Determinação de locais ótimos para implantação de torres de vigilância a incêndios florestais por meio de sistema de informações geográficas. $125 \mathrm{f}$. Dissertação (Mestrado em Ciências Geodésicas) - Setor de Ciências da Terra, Universidade Federal do Paraná, Curitiba, 2006. 